\title{
Evaluation of a New Salivary Gland Massage with Oil for Elderly Nursing Home Residents
}

Koji Ono $^{1^{*}}$ and Kimio Uchiyama ${ }^{2}$

${ }^{1}$ Japan Skincare Association, Tokyo, Japan

${ }^{2}$ Department of Dentistry and Oral Surgery, Tochigi Medial Centre, Tochigi, Japan

\begin{abstract}
We developed a new method of salivary gland massage to improve the symptoms of dry mouth in elderly nursing home residents. This method represents an improvement over previous methods because of the simplicity of the procedure and the speed at which it can be performed. We also use oil that reduces friction and moisturizes the skin. The massage technique effectively increased salivary secretion, at least as effective as what has been reported with other methods. Both caregivers and elderly nursing home residents approved this new method for its ease of use and comfort.
\end{abstract}

\section{Publication History:}

Received: November 20, 2016

Accepted: February 01, 2017

Published: February 03, 2017

\section{Keywords:}

Salivary gland, Massage, Elderly nursing, Oil

\section{Introduction}

Xerostomia is increasing in Japan due to the aging society, increased stress, irregular eating habits, and it is estimated that there are about 30 million potential patients in Japan. [1]There are a variety of treatment methods for dry mouth, including artificial saliva, humectant $[2,3]$ and salivary gland massage, that have been performed in Japan $[4,5]$ and in other countries as well $[6,7]$. Salivary gland massage manualized by Hara is used as a standard in Japan[5]. However, previous methods of salivary gland massage are complicated and time consuming, which presents a barrier for daily use among elderly nursing home residents. Xerostomia causes discomfort in the oral cavity and is associated with eating disorders, swallowing disorders, and deterioration of oral symptoms causing a decrease in quality of life. So, improvement in xerostomia is important to improve quality of life in elderly people.

We, therefore, developed a simple, quick and effective salivary gland massage for nursing home residents and evaluated its effectiveness.

\section{Materials and Methods}

\section{Procedure for newly developed salivary gland massage with oil:}

The performer, after dipping both hands in the oil, stood behind the seated subject and placed the middle and little fingers under the subject's mandible. One-way stroke massage was performed by sliding four fingers from the top of the mandible, passing the angles of the mandible and reaching the parotid glands under the masseter muscles. To avoid an aromatic effect of the oil, which may increase salivary secretion by itself, we used unscented oil. Finger pressures were controlled to not exceed the range at which the participant felt comfortable.

\section{Preliminary study with normal adult subjects:}

A total of 12 participants [men:women $=8: 4$, age $($ mean \pm SD) $=$ $35.3 \pm 9.9$ years] were enrolled into the preliminary study. Volumes of saliva before and after the massage were compared. Duration of the massage was either $1 \mathrm{~min}$ or $3 \mathrm{~min}$ per trial, and each participant was massaged for one trial with each massage duration for comparison. We measured the volume of saliva after the participants chewed on a cotton ball for $10 \mathrm{~min}$.

\section{Main study with nursing home residents:}

Elderly nursing home residents participated in the main study with their informed written consent or that of their closest relative if they were unable to sign the consent. To evaluate the efficacy and the ease of use of the new massage method, we measured the following: 1) volume of water and saliva secretion in the mouth before and after the massage, 2) concentration of water and volume of saliva in the mouth after the massage had been performed twice daily for 2 weeks and 3) administration of a questionnaire for nursing home caregivers who performed the new massage (Table 1).

1. Duration of the massaage
too short
approprite
2. Technic of the Message
Simple
Difficult
3. Usage of oil
favourable
unfavourable
4. Reaction of the Subject
Seems contented
Seems Uncomfortable
No particular reaction
Yes to adopt this technic
No
If required

Table 1: Questionnaire for the nursing home caregivers who performed the new massage.

\section{Participants}

Of the 15 nursing home residents for whom informed consent had been obtained (either from the resident or from the residents' closest family member if they were unable to consent),

"Corresponding Author: Koji Ono, Japan Skincare Association, Tokyo, Japan, Tel: +81-6411-9895, Fax: +81-6411-9077; E-mail: esthe.oji@gmail.com

Citation: Ono K, Uchiyama K (2017) Evaluation of a New Salivary Gland Massage with Oil for Elderly Nursing Home Residents. Int J Phys Ther Rehab 3: 129. doi: https://doi.org/10.15344/2455-7498/2017/129

Copyright: @ 2017 Ono et al. This is an open-access article distributed under the terms of the Creative Commons Attribution License, which permits unrestricted use, distribution, and reproduction in any medium, provided the original author and source are credited. 
12 participants were determined to be able to participate in this study and received the 2 -week course of salivary gland massage by their caregivers. From 10 subjects, four males and six females, at least one of three measurement terms were obtained for further analysis. Their mean age was $77.6 \pm 10.9$ years. The grade of care need, a method of quantifying disability related needs by the Japanese nursing care insurance system in which a grade of 5 represents the most severe level of disability, was applied to study participants, and the grades ranged between 3 and 5 , with the mean grade of $4.8 \pm 0.6$. Past medical history of participants included six cases of cerebrovascular disease, two cases of hypertension, three cases of dementia, two cases of Parkinson disease, five cases of diabetes mellitus, two cases of heart disease and other conditions not mutually exclusive; medications taken by participants included tranquillizers, antidepressants, antiparkinsonism medications, hypotensive medications, diuretics, diabetes medicines, emetics and antitussives; participants were taking a mean of approximately six medications. Three participants were nourished through the gastrostomy tube.

\section{Measures}

Tongue moisture was measured using a mucous membrane moisture test paper (KISO-WeT ${ }^{\oplus}$, KISO-DMSS, Japan). After placing the test paper on the midline of the dorsal surface of the tongue 10 $\mathrm{mm}$ from the tip for $10 \mathrm{~s}$, the length of the wet portion of the paper was measured as the moisture value. Water concentration in the mouth was measured at the same location and also at the middle of the cheek mucous membrane by an impedance method with an oral water concentration measuring system (KokusuibunkeiMucus ${ }^{\oplus}$, Life, Japan). Amount of saliva was measured by the Saxon test by chewing on a folded sterile sponge for $1 \mathrm{~min}$.

\section{Statistical analysis}

All data analysis was performed using the Mann-Whitney U-test with IBM SPSS statistics ver.19. Differences of $p<0.05$ were considered significant.

\section{Results and Discussion}

\section{Preliminary study with healthy adult participants:}

Volume of saliva secretion was significantly increased after the 1-min massage, while the mean secretion volume after 3 min was less than that measured after the 1-min massage and not significantly different from before the massage (Table 2).

\begin{tabular}{|l|l|l|}
\hline & $\begin{array}{l}\text { amount } \\
\text { s a l i v a ( c c / 1 } \\
\text { min } \pm \text { SD) }\end{array}$ & P-Value \\
\hline Base Line & $15.8 \pm 5.1$ & \\
\hline After 1 min. massage & $17.4 \pm 6.1$ & $0.016^{*}$ \\
\hline After 3 min. massage & $16.7 \pm 5.7$ & 0.083 \\
\hline $\begin{array}{l}\text { Table 2: Increase of saliva excretion after massage } \\
* P<0.05 \text { (a significance value) }\end{array}$
\end{tabular}

Main study with elderly nursing home residents:

\section{Effect of the new massage}

Regarding the moisture in the mouth, slight increases were seen just after the massage and after the 2-week course of massage, although neither was statistically significant.
Regarding the water concentration in the mouth, no detectable change was seen on the dorsal surface of the tongue, but significant increase in water concentration was observed on the cheek mucous membrane after the 2-week course of massage twice daily.

Regarding the secretion of the saliva, a significant increase was seen in saliva volume between before and after the massage.

\section{Questionnaire for caregivers:}

Twenty-five caregivers completed the questionnaire. Regarding massage duration, 24 caregivers responded that the duration was 'appropriate' and one responded that the duration was 'too short'. Regarding the relative ease or difficulty of performing the new massage technique, 23 responded 'easy' and two responded 'difficult'. Regarding the use of massage oil, all 25 responded as 'favourable', although one commented that he thought it may be difficult to find an appropriate quantity of oil for this massage. Regarding the reaction of the participants, 19 caregivers reported that the participant seemed to be 'contented', six reported no reaction and four reported the participant seemed to be 'uncomfortable. As for the continuation of the massage service, 12 caregivers responded 'yes', 12 responded 'if required' and one selected both 'yes' and 'if required'. Some caregivers also commented that the time for massage can be also used as time for verbal communication between caregivers and elderly nursing home residents.

In adult healthy subjects, the volume of saliva secretion after a 1-min massage was greater than after a 3-min massage and that the volume increase from just prior to the massage was statistically significant. Therefore, we concluded that the 1-min massage is appropriate for use in the nursing home.

Most elderly nursing home residents have dementia or cerebrovascular diseases and cannot independently perform adequate oral care to maintain oral health. Additionally, many have symptoms of dry mouth due to medication side effects or underlying medical conditions.. Generally, nursing homes tend to be dry and are inhabited by many elderly peoples who need humidifiers and moisture creams throughout the year to prevent the drying of their skin. Previous methods of facial and salivary gland massage present a small, but not negligible risk of friction injury to the dehydrated skin of the face.. We used oil to avoid this risk and to help moisturize the skin. We attribute the positive reception that this method received from caregivers and nursing home residents, as was demonstrated by the results of the questionnaire, to the use of the oil.
A

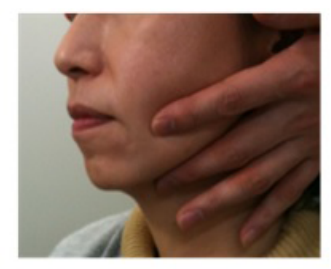

B

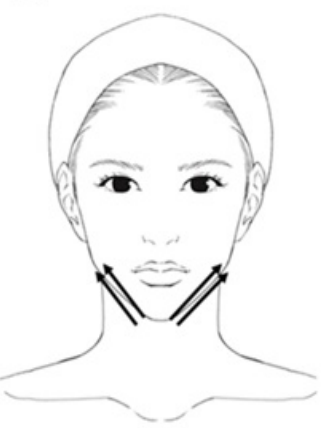

Figure 1: Positioning (A) and Moving Direction (B) of Fingers in Saliva Gland Oil Massage. 
Citation: Ono K, Uchiyama K (2017) Evaluation of a New Salivary Gland Massage with Oil for Elderly Nursing Home Residents. Int J Phys Ther Rehab 3: 129. doi: https://doi.org/10.15344/2455-7498/2017/129

Page 3 of 3

The efficacy of our new salivary gland massage on increasing saliva secretion is at least equal to the reported efficacy of previous salivary gland massages.

Regarding the duration and simplicity of the massage, the results of the questionnaire are sufficient to satisfy the aim of the present study, which was to establish the efficacy of a simple, quick and easyto-administer salivary gland massage to alleviate symptoms of dry mouth in elderly nursing home residents. This new method is easy to learn. For the 1-min massage, 45-50 strokes are required, and counting the strokes aloud instead of measuring time by a clock helps produce a rhythmical massage and facilitates good communication between caregivers and elderly residents.

Results of the questionnaire, however, also showed that about half of the caregivers are not willing to do this massage unless it is required, though they admit it has benefits for the recipient. This issue may be secondary to the inadequate staffing that is common in among nursing homes in Japan.

Additionally, changing unscented oil to aromatic oil may increase this method's effects, as aromatic oil may stimulate the CNS to increase saliva secretion.

Several benefits of body massage have also been reported [8], including such as enhanced immune function and increased IgA concentration in saliva [9]. The salivary gland massage itself may be expected to improve immune function in addition to increasing saliva secretion.

It is considered that saliva productivity was increased by repeating direct stimulation through the feedback system though the exact mechanism is uncertain.

The effect of maxillofacial massage by a specially developed robot has also been reported with significant increase in saliva secretion as well [10].

\section{Conclusion}

We developed new method of salivary gland massage with oil and evaluated its utility in a nursing home environment. Our method's effect on saliva secretion is, at least, equivalent to the effect reported by previous methods. In addition, our method features a simple and easy to acquire technique and is more comfortable for participants to the use of a friction-reducing and moisturizing oil. As an unexpected effect of massage, caregivers reported that this method provides a good opportunity to communicate with nursing home residents while performing the massage.

\section{Competing Interests}

The authors declare that they have no competing interests.

\section{Acknowledgement}

We are grateful to Dr. Takahiko Asai, permanent director of Japan Aroma-coordinator's Association, general manager Mrs. Hisako Ito and the nursing home staff of Yokohama City Urafune Home for their cooperation in this study.

\section{Funding}

This work was supported by a grant (Health, Labour and Welfare Grants-in-Aid for Scientific Research of longevity Sciences) and reported to the Ministry of Health, Labour and Welfare [11].

\section{References}

1. Mashimo J, Okane M, Sato Y, Kitagawa N, Kitamura Y (2008) Relationship between Oral Dryness and Properties of Saliva (I): Healthy Adults. Japanese Journal of Gerodontology 23: 319-329.

2. Navazesh M, Ship II (1983) Xerostomia: Diagnosis and treatment. Am J Otolarygol 4: 283-292.

3. Villa A, Connell CL, Abati S (2015) Diagnosis and management of xerostomia and hyposalivation. Ther Clin Risk Manag 11: 45-51.

4. Oyamada S, Ohara S, et al. (2006) Effect the introduction of the salivary glands massage to dry mouth. Kango Sogo 37: 80-82.

5. Hara K (2008) Study on activation of salivary secretory function with salivary gland massage. J. Hiroshima Univ. Dent Soc 40: 10-29.

6. DeBar LL, Vuckovic N, Schneider J, Ritenbaugh C (2003). Use of complementary and alternative medicine for temporomandibular disorders. J Orofac Pain 17: 224-236.

7. Riley III JL, Myers CD, Currie TP, Mayoral O, Harris RG, et al. (2007) Selfcare behaviors associated with myofascial temporomandibular disorder pain. J Orofac Pain 21: 194-202.

8. Groer M, Mozingo J, Droppleman P, Davis M, Jolly ML, et al. (1994) Measures of salivary secretory immunoglobulin $A$ andstate anxiety after a nursing back rub. Appl Nurs Res 7: 2-6.

9. Ironson G, Field T, Scafidi F, Hashimoto M, Kumar M, et al. (1996) Massage therapy is associated with enhancement of the immune system's cytotoxic capacity.Int J Neurosci 84:205-217.

10. Ishii H, Koga H, Obokawa Y, Solis J, Takanishi A, Katsumata A (2009) Development and experimental evaluation of oral rehabilitation robot that provides maxillofacial massage to patients with oral disorders. Int J Robot Res 28: 1228-1239.

11. Uchiyama K, Koji O (2011) Usefulness of the new salivary gland oil massage in care facility. (in Japanese) in the report to the MHLW "Study on the survey and the development of standard care guidelines of the dry mouth of the elderly". $82-86$ 